\title{
Apuntes para construir un método analítico desde el feminismo jurídico queer*
}

\author{
Notes to build an analytical method \\ from Queer Legal Feminism
}

\author{
MANuel SÁNCHEZ-MoReno** \\ Universidad Internacional de La Rioja (UNIR) \\ ORCID ID: 0000-0002-2463-1208
}

Recibido: $26 / 2 / 2020$

Aceptado: $10 / 12 / 2021$

doi: https://doi.org/10.20318/femeris.2022.6623

\begin{abstract}
Resumen. Los feminismos llegan a los derechos humanos para decir que la igualdad y la universalidad se ha construido dejando fuera a determinados sujetos, como las mujeres o la diversidad afectivo-sexual. La teoría crítica también ensancha los derechos y los sujetos, en el marco de las luchas sociales. Todo ello arroja nueva luz, para cuestionar primeramente la construcción del derecho y, posteriormente construir e interpretar leyes considerando a toda la humanidad. Las identidades previamente excluidas reclaman ahora una presencia mayor y unas experiencias infrarrepresentadas. Los feminismos han descubierto que el derecho es un ámbito del heterocispatriarcado y que la ley y su interpretación debe contemplar experiencias de personas tradicionalmente excluidas. Desarrollan herramientas para demostrar su desprotección e invisibilización ante el derecho. Partiendo de las propuestas teóricas feministas y de una evolución de la normativa se analizan las principales causas de este sesgo legal como la forclusión o el fundacionalismo. También se retomarán elementos que consideramos clave para huir de un análisis esencialista, como la interseccionalidad, la inclusión de las personas LGTBIQA+ o las manifestaciones del sexismo. Finalmente se propondrá una metodología desde el feminismo jurídico queer que sea un punto de partida para analizar, interpretar y formular textos normativos sensibles a género. Seguiremos estudios de Iris Young, Martha Nussbaum, Catharine Mackinnon, Nancy Fraser, Margrit Eichler o Alda Facio.

Palabras clave: feminismo jurídico, género, diversidad afectivo-sexual, queer, sexismo.
\end{abstract}

Abstract. Feminisms put the focus on Human Rights to say that equality and universality has been built leaving out certain subjects, such as women or affective-sexual diversity. Critical theory also addresses rights and subjects, within the framework of social struggles. All this shed new light, to first questioning the construction of law and, later, to build and interpret laws considering all humanity. The identities excluded previously, claim now a greater presence and underrepresented experiences. Feminisms have discovered that Law is an area of heterocispatriarchy and that the Law and its interpretation must contemplate experiences of traditionally excluded people. The Feminisms develops tools to demonstrate the lack of protection and invisibility before the Law. Starting from the Feminist theoretical proposals and an evolution of the

${ }^{*}$ Fue escrito gracias a una estancia de investigación en el Instituto de Estudios de Género de la Universidad Carlos III de Madrid. Mi agradecimiento al Instituto y a la Profesora Rosa San Segundo Manuel, así como a la Revista, por las correcciones sugeridas para mejorar el presente texto.

**manuel.sanchezmoreno@unir.net 
Standards, the main causes of this legal bias such as forclusion or foundationalism are analyzed. Elements that are considered key to avoid an essentialist analysis, such as intersectionality, the inclusion of LGTBIQA+ people or the manifestations of sexism will also be retaken. Finally, a Queer Legal Feminism methodology will be proposed as a starting point for analysis, interpretation and formulation of gender-sensitive normative texts. We will follow studies of Iris Young, Martha Nussbaum, Catharine Mackinnon, Nancy Fraser, Margrit Eichler or Alda Facio.

Keywords: feminist legal theory, gender, effective-sexual diversity, queer, sexism.

\section{Introducción}

En este articulo nos planteamos el objetivo de diseñar una metodología que permita el análisis jurídico y sus textos con un enfoque de género y de diversidad afectivo-sexual, que incorpore a las mujeres, a las personas LGTBIQA $+{ }^{1} \mathrm{y}$ a las sexualidades no normativas derivadas de la teoría queer. Todo ello siguiendo una metodología de análisis de contenidos. Benjamin (1973) afirmaba: "jamás se da un documento cultural sin que lo sea al mismo tiempo de la barbarie" (p.101). Con esta frase, resume el carácter dialéctico y poroso de la producción humana que puede ir desde las Bellas Artes hasta la elaboración de textos normativos, pasando por la industrialización y el problema ecológico. Y a la vez nos anima a buscar nuevas formas de ver y analizar estos documentos y realidades. A desarrollar una visión crítica. ¿Lo podemos aplicar también a documentos tan sacralizados como incumplidos como la Declaración Universal de Derechos Humanos?

La Declaración Universal de los Derechos Humanos (1948) surge como consecuencia del nuevo orden mundial. El imperativo de esta Declaración es proponer un concepto ético de dignidad de la persona desde la universalidad de estos derechos humanos. Pero esta propuesta emancipatoria de la humanidad es irrealizable debido a la exclusión de identidades operada mediante la interpretación del texto normativo.

Ocupándose de esta problemática, el feminismo jurídico como instrumento de lucha por los derechos de las mujeres (nada menos que la mitad de la población) y las personas LGTBIQA+, ha realizado aportes que han ido generando cambios en todos los aspectos: social, político, cultural y jurídico, para intentar incluir a sujetos tradicionalmente excluidos en la construcción del mundo y de la titularidad de derechos: mujeres, grupos étnicos, personas con capacidades diferentes, personas en situación de pobreza, diversidad afectivo-sexual, etc. ensanchándose el proyecto social y de justicia del feminismo a otros colectivos. Recordemos que los primeros movimientos organizados de mujeres que luchaban por sus derechos, allá por el siglo XVIII, también se fijaron y lucharon por los derechos de otras personas infrarrepresentadas, como por ejemplo esclavos, pobres y posteriormente se establecieron alianzas con movimientos de liberación LGTBIQA+, mejor o peor avenidos. Estas nuevas visiones critican la invisibilización de las mujeres y de las personas que no participan de la sexualidad normativa en el proyecto de derechos humanos y de

\footnotetext{
${ }^{1}$ Lesbianas, gays, trans, bisexuales, intersexuales, queer, asexuales. Lo queer y el '+' en alusión a aquellas prácticas, identidades y expresiones no binarias y no incluidas en los anteriores conceptos. Aunque incluir lo queer en unas siglas y un colectivo es contrario como veremos a lo queer, ya que evita cualquier categoría. Por esta razón usaremos estas siglas y lo queer de manera diferenciada.
} 
ciudadanía, ya que ofrecen una visión construida en torno a las necesidades, experiencias y aspiraciones del varón heterosexual y cisgénero ${ }^{2}$.

En definitiva, personas que, en la interpretación que se hace de la Declaración Universal de los Derechos Humanos, no se tenían en cuenta, siendo necesaria la especificación. Esto crea bolsas de derechos para personas "diferentes". Véase por ejemplo la Conferencia de Derechos Humanos de Viena (1993), donde afirma la indivisibilidad, interdependencia y mismo peso de los derechos (Sánchez-Moreno, 2011), así como que los derechos de las mujeres y las niñas son también derechos humanos, como consagra la Convención sobre la eliminación de todas las formas de discriminación contra la mujer (CEDAW, 1979) (Sánchez-Moreno, 2012). El reto ahora es conseguir un consenso internacional que haga exigibles y judiciables los derechos de la diversidad afectivo-sexual.

En este texto no sólo intentamos visibilizar y sumar colectivos y temas que han tenido un acceso deficitario a la justicia, sino deconstruir los modos de hacer del derecho. Este ejercicio nos parece estructural porque ¿qué sentido tiene visibilizar si no se cambian las estructuras misóginas y homófobas/transfóbicas con los que se aplica la justicia en términos generales? De otra manera se crean modos sostenibles de convivir con este tipo de justicia, que genera alguna casuística positiva en favor del género y la diversidad afectivosexual, pero en absoluto un procedimiento en un mundo de "varones".

En esta propuesta metodología no sólo hablamos de mujeres, sino que ampliamos a la diversidad afectivo-sexual, donde se encuentran las las personas LGTBIQA+ y las sexualidades no normativas y no binarias. La razón es que el propio concepto de género está vinculado a usos, prácticas o funciones asignados a varones y mujeres, incluyendo la sexualidad y sus diferentes manifestaciones y prácticas más allá del binarismo varón/mujer. El párr. 5 de la Recomendación General 28 del Comité de la CEDAW explica que género:

Se refiere a las identidades, las funciones y los atributos construidos socialmente de la mujer y del hombre, y al significado social y cultural que la sociedad atribuye a esas diferencias biológicas, lo que da lugar a relaciones jerárquicas, entre hombres y mujeres y a la distribución de facultades y derechos a favor del hombre y en detrimento de la mujer.

\section{Hacia una teoría crítica de los derechos humanos}

El género y la diversidad afectivo-sexual han estado ausentes en la construcción de los Estados. Esto se debe a la sombra alargada de la Ilustración y su proyecto universalizador que tiene como medida al varón blanco heterosexual y cisgénero. Este hecho se denomina Contrato, una ética del consenso excluyente, ante el que la lucha social de los feminismos plantará cara.

Este contrato político subsume un "contrato sexual" que establece relaciones de dominación (varón) en la esfera pública, subordinación (mujeres, niñas, niños, etc.) en la

\footnotetext{
${ }^{2}$ Cisgénero se refiere a que la identidad de género autopercibida se corresponde con la asignada al nacer por su sexo biológico. Es lo contrario a transgénero.
} 
esfera privada y exclusión (mujeres reveladas, personas no heterocisexuales, disidencias sociales de etnia o clase, etc.) en la esfera criminal. Según Carole Pateman (1995, p.144), las mujeres no tenían cabida en el espacio público y político, ya que su destino era el de la esfera privada tutelada por los varones que dominan la esfera pública y racional. Del mismo modo los varones disidentes están del lado de la enfermedad y la criminalidad, estableciéndose una masculinidad excluyente respecto a los varones con una sexualidad no normativa (Amorós, 1991, p.30). Podemos decir que se genera un heterocispatriarca$\mathrm{do}^{3}$, como eje del sexismo o discriminación basada en el sexo que controla los cuerpos y prioriza la procreación (Figura 1).

Figura 1. Relaciones del heterocispatriarcado.

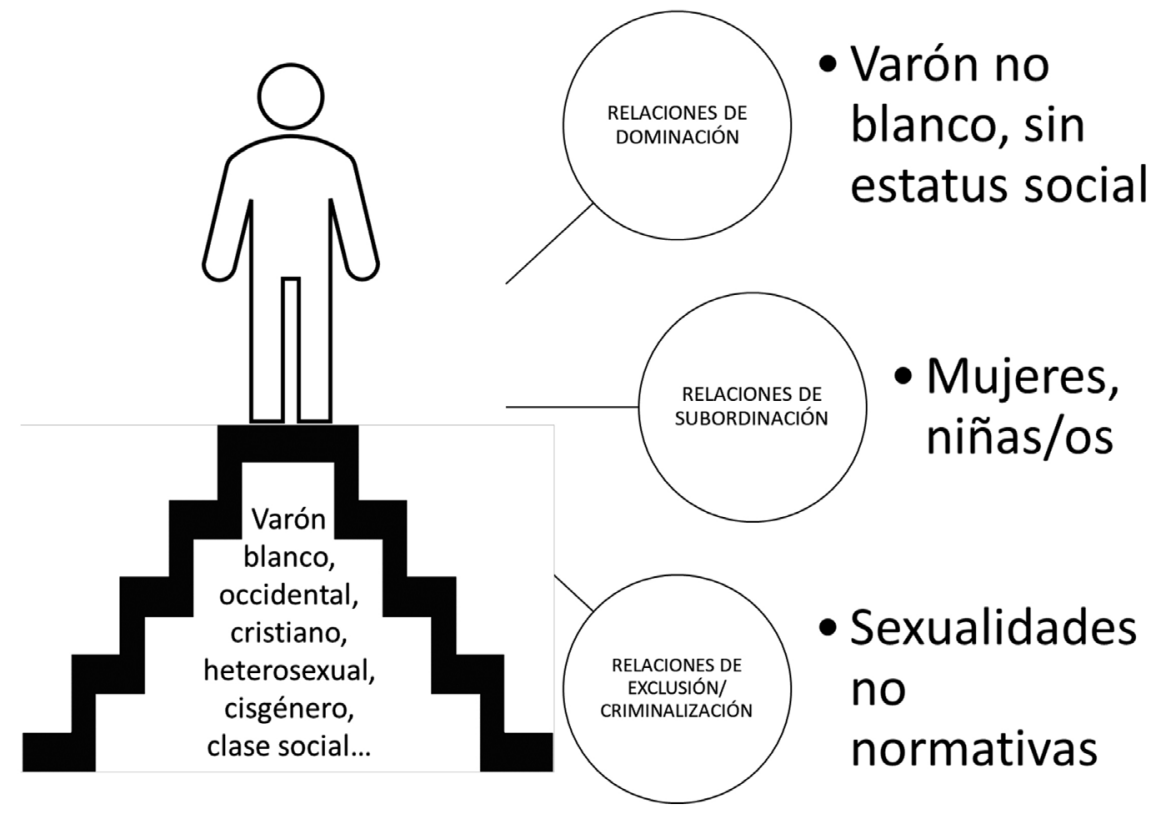

Fuente: elaboración propia.

Tras la II Guerra Mundial y con el marco la Declaración Universal de los Derechos Humanos, las propuestas neocontractuales y liberales no cambiaron de tendencia. Esto se debe a que, a pesar de que el Contrato está roto y que las mujeres, las sexualidades no normativas y otros colectivos ya han sido reconocidos como titulares de derechos, su individualidad no es la misma que la del varón, ya que el modelo de igualdad se abstrae

\footnotetext{
${ }^{3}$ El patriarcado, concepto acuñado por Kate Millet, como el dominio de los varones sobre las mujeres, supone también un dominio de unas identidades afectivo-sexuales y de género (heterosexualidad y cisgénero) normalizadas y hegemónicas sobre otras. El patriarcado fue seguido por otras feministas como Gerda Lerner y criticado por Gayle Rubin para la que es "importante distinguir entre la capacidad y necesidad humanas de crear un mundo sexuado y las formas empíricamente opresivas en que los mundos sexuales han sido organizados. El término patriarcado subsume ambos significados en uno sólo" (Osborne y Molina, 2008, p.152). Rubin propone el sistema de sexo-género ya "que la opresión no es inevitable sino el producto de las relaciones sociales específicas que la organizan" (Osborne y Molina, 2008, p.152). Ambos conceptos pueden conciliarse si entendemos al patriarcado -o al heterocispatriarcado-, como un sistema que no necesariamente tiene que estar amarrado a una sexualidad hegemónica, sino a una herencia y práctica cultural que impregna a todos los órdenes de la realidad y a todos los sujetos. Es justo esto lo que hace que una sociedad transforme la sexualidad biológica en productos de la actividad humana y en unas jerarquías de géneros.
} 
en la masculinidad hegemónica. Las nuevas personas incluidas lo hacen sin modificar el patrón cultural y atávico del contrato sexual, construido en base al binomio jerarquizado y esencialista del varón/mujer estereotipados.

Pero tener una herramienta tan poderosa como la Declaración Universal de los Derechos Humanos legitima aún más las luchas sociales que reclaman una universalidad real de estos derechos, avanzando en tres direcciones: más bienes, más sujetos y más identidades (Bobbio, 1990, p.72).

Más bienes tutelados: más allá de una clasificación arquetípica entre derechos civiles y políticos, y derechos económicos, sociales y culturales hay una proclamación de la interconexión de todos, unida con la emergencia de los bienes públicos como derechos y los derechos colectivos como el medioambiente, la paz o el desarrollo.

Más sujetos: más allá de los derechos individuales de la persona, se pasa a los derechos de los colectivos: las mal definidas minorías se reconfiguran y amplían. Todo aquello que no es un individuo y es susceptible de proteger por su vulnerabilidad y por pertenencia a un grupo o a un colectivo de bienes.

Más identidades: se da la evolución de los derechos del "hombre"4 en abstracto, a los derechos de las personas en sus diversas facetas visibilizadas, por ejemplo, a través del género, la diversidad afectivo-sexual, la etnia, situación de desplazamiento, refugio o migración, etc.

Como vemos los derechos humanos son históricos en tanto que evolucionan con la humanidad, sus identidades y sus luchas, y su ampliación debería verse como algo natural y sin obstáculos (Herrera, 2007). Bajo este prisma, los movimientos sociales y sus protestas, a menudo ignorados en las conquistas políticas y jurídicas, son fundamentales para la institucionalización de nuevos derechos e identidades que responden a antiguas realidades. Los feminismos forman parte de estas luchas, al igual que otros movimientos como los étnicos o los de liberación LGTBIQA+, ante la crisis de representatividad democrática y con un principio de solidaridad ante los demás, especialmente hacia el "otro" históricamente marginado que, consciente de la exigibilidad de los derechos lucha por su justiciabilidad, en un punto de no retorno (Rodríguez, 2011).

La universalidad excluyente es cuestionada por una teoría crítica de los derechos humanos basada en las luchas sociales como motores de su consecución y no en conceptos abstractos y jurídicamente indeterminados como que son innatos, universales o indivisibles. Es la lucha por los derechos de las personas en su diversidad de identidades, expresiones y situaciones. En este sentido y siguiendo a Amelia Valcárcel (1994), los logros feministas en el ámbito político y legal se han efectuado mediante actos subversivos como las manifestaciones, modificando el orden heterocispatriarcal de las cosas.

Comanducci (2000, pp.24-25) afirma que a veces se sostiene que estos derechos no se interpretan como referidos a todos los seres humanos, ya que no todos los seres humanos son considerados con características tan valorables como para ser titulares de estos

\footnotetext{
${ }^{4}$ Entendido en el sentido liberal restringido al varón, pero también aprovechando la ambigüedad lingüística que ofrece el masculino en su condición universal.
} 
derechos. Hay dos vías para este planteamiento: se excluye la titularidad de los humanos marginales o se incluyen a todos los seres humanos, que es la lucha de los feminismos. Frente a esto los feminismos parten de: "el derecho a tener derechos" (Arendt, 2004: 420) y "ningún ser humano es ilegal" (Benhabib, 2006, p.127).

Esto lleva a otra cuestión sobre el fundamento de los derechos humanos: ¿es una cuestión más moral o jurídica? Por un lado, el iusnaturalismo aboga por unos derechos que están más allá del reconocimiento jurídico, es una condición a priori basada en la dignidad humana. Por otro lado, el iuspositivismo plantea que sólo existen estos derechos una vez se reconocen jurídicamente a través de leyes, constituyendo un elemento a posteriori.

Tanto Comanducci como Bobbio (1999, p.16) afirman que este dilema no es muy práctico hoy en día, toda vez que ambas categorías están dentro de Constituciones nacionales y Tratados internacionales, y que el verdadero problema es proteger los derechos (cuestión política) y no tanto justificarlos (cuestión filosófica). Bajo un prisma éticamente humano y filosóficamente humanístico cualquier persona tiene derecho a tener derechos como mencionaba Arendt. Y es tener conciencia de este razonamiento lo que hace que sean reclamados.

Esta postura, que defiende los principios de universalidad e igualdad ampliándola a las mujeres y otros grupos infrarrepresentados como la diversidad afectivo-sexual, se enfrenta a otra que critica ambos conceptos como una trampa que sigue operando y que se debe desechar trabajando desde la diferencia, como sostienen Iris Young (1990) o Judith Butler (2007: 70). Esta última autora desarrolla la teoría queer, concepto acuñado por Teresa De Lauretis $(1991)^{5}$, como un rechazo al binarismo varón/mujer y la apuesta por una serie de identidades performativas, múltiples y electivas. Las identidades queer de Butler abren a más experiencias sexo-genéricas no binarias. Se centran en una sexualidad performativa que escapa a la construcción heterosexualidad/homosexualidad (Sedgwick, 1998).

Estas posturas son complementarias y necesarias, la de una identidad de las mujeres identidades LGTBIQA+ y la de una identidad sexual flexible, no normativa y no binaria (no-identidad) de las personas dentro del Estado, ya que se ocupan de problemáticas opresivas derivadas del sexo, del género y de la sexualidad.

\section{La interseccionalidad de género como reivindicación de derechos humanos}

Para evitar hacer un análisis esencialista no basta sólo con considerar al género como un asunto de diversidad afectivo-sexual, sino también como una cuestión conexa a otras problemáticas. Es decir, interseccional.

\footnotetext{
${ }^{5}$ Lo queer como concepto es acuñado por Teresa De Lauretis en la conferencia "Queer Theory: Lesbian and gay Sexualities", pronunciada en febrero de 1990 en la Universidad de California, en Santa Cruz. Se recogerá por escrito un año más tarde en la revista differences. Lo queer se plantea inicialmente como una crítica a la homogeneización del término "minorías sexuales" y a la ocultación de lo lésbico. Se propone como "otro horizonte discursivo, otra manera de pensar lo sexual" (De Lauretis, 1991, p.iv). Debemos aclarar que el concepto queer no sólo ha recibido críticas desde buena parte del movimiento feminista, sino desde otros entornos que ven una excesiva teorización y despolitización del término, razón por lo cual, De Lauretis (1994) lo criticó duramente al considerar que "se ha convertido muy rápidamente en una criatura conceptualmente vacía de la industria editorial" (p.296). Desde lo decolonial en Latinoamérica se habla de lo cuir o cuy(r) y desde el activismo de lo kuir, para buscar resignificaciones alejadas del elitismo teórico de la academia y acercarlo a la práctica.
} 
El debate de la interseccionalidad surgió en el centro del feminismo negro estadounidense, que, partiendo de las diferencias, criticaron al feminismo esencialista y a las luchas contra la discriminación racial que ignoran el género, apostando por una estrategia de insubordinación ante el patriarcado (Johnson, 2005, p.21). Proponían la conexión de diferentes componentes de la identidad que, hasta ese momento, eran considerados de manera separada. El concepto va más allá de juntar identidades separadas para proponer una única identidad perteneciente a varias categorías. Esto amplía el derecho antidiscriminatorio clásico, donde las causales son limitadas y paralelas, jamás se cruzan.

Kimberlé Crenshaw (1989) emplea por primera vez el término "interseccionalidad" en 1989 cuestionando la tendencia a tratar la raza y el género como categorías de experiencia y análisis excluyentes y no complementarios. El concepto aparecerá después en la Declaración y Plataforma de acción de Beijing (IV Conferencia Mundial de la Mujer, 1995), la Observación General 28 del Comité de Derechos Humanos (2000), la Recomendación General 25 del Comité para la Eliminación de la Discriminación Racial (CEDR) (2000) o la III Conferencia contra el Racismo de Durban (2001). El PNUD (2009) definió interseccionalidad como "la discriminación compuesta, doble o múltiple y referida a la interacción entre dos o más formas de discriminación".

En torno a las teorías de Crenshaw y en el ámbito socio-jurídico, se produjeron una serie de reacciones que por un lado criticaban el concepto y por otro lo ampliaban y complementaban. La propia autora veía en la interseccionalidad un concepto de transición que puede ser reemplazado por un entendimiento más multidimensional (Crenshaw, 1993, p.111). Patricia Hill Collins, parte de Crenshaw y de la "política de la dominación" de bell hooks para afirmar que los patrones culturales de opresión que generan la discriminación interseccional no sólo están interrelacionados, sino unidos bajo una misma matriz que abarca la raza, el género, la clase y la etnicidad, a la que llamó “opresión entrelazada”. (Hill Collins, 1990, p.18).

Por otro lado, la post-interseccionalidad, término acuñado por Kwan (1997), amplía el término y lo enriquece como estrategia política de otras identidades, demostrando que la interseccionalidad no sólo es cuestión del género y la raza o etnia, sino que incluye la clase social, las capacidades diferentes y la diversidad afectivo-sexual (Bowleg, 2008). En línea con Hill Collins, la diversidad afectivo-sexual emerge con fuerza en el discurso postinterseccional, basándose en que las formas de subordinación heterocispatriarcal sobre el género, la raza/etnia, la clase social y la diversidad afectivo sexual están entrelazadas y responden al mismo patrón.

Hutchinson propone la multidimensionalidad que "reconoce la inherente complejidad de los sistemas de opresión y las categorías de identidad social en torno a las cuales el poder social y el desempoderamiento es distribuido" (Hutchinson, 1999, p.9). Es decir, propone analizar los patrones de subordinación que producen las discriminaciones interseccionales, y ver como estos patrones están interconectados en un eje heterocispatriarcal, que excluye intereses sociales y jurídicos de personas con identidades no hegemónicas (Valdés, 1998). Sólo con un análisis multidimensional se puede dar una respuesta no esencialista ante la discriminación. Elvia Arriola (1994) apremia un análi- 
sis holístico desde el punto de vista jurídico para identificar los estereotipos que actúan de manera nociva. Por otro lado, Kwan (2000), explicando su propuesta de "cosíntesis" afirma que no hay una identidad por encima de otra: clase social sobre raza, raza sobre género o género sobre orientación sexual; la subordinación múltiple sintetiza todas las categorías identitarias.

La Recomendación General 28 (2010) alude de manera explícita a la intereseccionalidad en el párrafo 18: "La discriminación de la mujer por motivos de sexo y género está unida de manera indivisible a otros factores que afectan a la mujer, como la raza, el origen étnico, la religión o las creencias, la salud, el estatus, la edad, la clase, la casta, la orientación sexual y la identidad de género."

A pesar de todas estas elaboraciones, la tendencia predominante del derecho antidiscriminatorio es lineal respecto a sus causales. Es complicado aplicar jurídicamente la interseccionalidad y se ha buscado otro concepto, el de "discriminaciones múltiples", que no señala esas nuevas formas de discriminación y opresión que se crean sobre la conexión de otras. Tan sólo propone señalar la coincidencia, sin más, de varios factores discriminatorios en una persona (Makkonen, 2002).

\section{El feminismo jurídico como metodología emancipatoria}

Si hacemos una definición del término, feminismo según el Diccionario de la Real Academia Española de la Lengua es el "principio de igualdad de derechos de la mujer y el hombre. Movimiento que lucha por la realización efectiva en todos los órdenes del feminismo". Debemos incluir aquí también la definición aportada por el Diccionario María Moliner: "doctrina que considera justa la igualdad de derechos entre mujeres y hombres. Movimiento encaminado a conseguir esta igualdad". Las definiciones nos dan dos claves: la igualdad y el movimiento social. Este último no alude a una tendencia uniformada, sino diversa. Por lo tanto y partiendo del concepto de igualdad en la dignidad de mujeres y varones, se puede hablar de feminismos, en plural, como diversas maneras de aproximarnos a este concepto, y de luchar por él.

Todo esto ha hecho que las distintas tendencias del feminismo se organicen o bien por olas siguiendo una lógica histórica, o bien por corrientes bajo distintos prismas teóricos. Las olas han ido desde la primera centrada en el sufragismo y en la igualdad jurídica hasta la actual cuarta ola marcada por la globalización, el ciber activismo y la reacción contra los postfascismos o partidos de extrema derecha radical (Sánchez-Moreno, 2020).

Las disquisiciones teóricas resultan más interesantes para este artículo. La más básica e institucionalizada es el feminismo de la igualdad, de cuño liberal, que procura la positivación de los derechos de las mujeres en el ámbito legal. Por su lado, el feminismo radical pone el acento en que no basta con crear leyes igualitarias y antidiscriminatorias, es necesario cuestionarse el sistema, heterocispatriarcal que necesita ser modificado en base a las diferencias entre mujeres y varones. Se incluyen cuestiones raciales o culturales para dar voz a más mujeres. Una variación de estas elaboraciones a partir de la diferencia 
sería el transfeminismo, que cuestiona el biologicismo e incluye a otras mujeres no cisgénero. Esto está en relación con la teoría queer y las luchas LGTBIQA+.

A partir de aquí ha habido muchas variaciones, como el feminismo socialista, que incorpora las críticas al capitalismo y al modelo liberal, incluyendo el factor clase para señalar la desigualdad de las mujeres y su opresión. El ecofeminismo que incorpora las preocupaciones ecológicas, el feminismo negro alude a cuestiones de étnicas o el postcolonial surgido de las antiguas colonias e incorporando aspectos tan importantes como las mujeres en el islam o las mujeres indígenas. Aunque en todos ellos la base es la situación de desventaja de las mujeres y la lucha por la igualdad, van variando los sujetos, bienes e identidades, siguiendo una lógica crítica.

Esto evidentemente influencia al feminismo jurídico que también es plural y que lleva todas estas tendencias a unas visiones de crítica, construcción e interpretación del fenómeno jurídico muy diversas, dentro de los Critical Legal Studies, que ven al derecho como un instrumento para mantener la hegemonía de determinados grupos sociales. Desde un feminismo de la igualdad que promociona a las mujeres en igualdad de oportunidades respecto a los varones, hasta un feminismo radical que ve necesario resaltar estas diferencias en la ley, con medidas de equidad, por ejemplo y yendo más allá de la ley ${ }^{6}$.

Como otra línea están los LGTB Legal Studies que se encargan de la inclusión de estos colectivos en el fenómeno legal (matrimonio gay, leyes trans, etc.). Y los Queer Legal Studies, a menudo identificados con los anteriores, pero que tienen dependencia de la teoría queer y del cuestionamiento identitario que hace (Fischel, 2019). Se encargan de todas aquellas personas no identificadas con siglas ni identidades, situaciones y prácticas preestablecidas que, en su categoría de ser humano (hasta aquí llegamos) necesitan, quizá no regulación ya que lo queer no lo desea, pero sí respeto y protección jurídica.

Influenciado por lo queer encontramos al transfeminismo, que incorpora a las mujeres trans dentro del discurso feminista. El feminismo lucha contra una biología determinista que, a su vez es el eje de todas las discriminaciones, y el transfeminismo busca lo mismo, pero no por el género asignado al nacer, sino por la autopercepción de este.

Aquí entramos en una de las problemáticas más intensas en los últimos tiempos. Frente a la cuestión de incluir a las mujeres trans como sujetos del feminismo junto a las mujeres, digamos, biológicas se han tomado dos caminos. Por un lado, el de parte del feminismo, que aboga por volver a lo biológico como punto de separación y eje del problema que define al sujeto del feminismo ${ }^{7}$. Por otro lado, la postura influenciada por lo queer y Butler (2007, p.47) indicando que acotar toda identidad (de género, sexo o sexualidad) es intrínsecamente opresiva y excluyente, en este caso hacia las mujeres trans.

Sobre esto último, Linda Alcoff (1988) dirá: "Y aquí está precisamente el dilema de las feministas: ¿cómo podemos fundamentar una política feminista que deconstruye al sujeto femenino?" (p.419). Y Teresa De Lauretis (1987):

\footnotetext{
${ }^{6}$ Para ver cómo aplicar desde el punto de vista práctico medidas de igualdad y equidad es necesario ver García (2016) y Kemelmajer (2001).

${ }^{7}$ Parte de esta tendencia se ha concretado en el movimiento TERF (Trans-Exclusionary Radical Feminist), es decir Feminista Radical Trans-Excluyente. Se les achaca de poner en práctica la transfobia, al igual que al movimiento Trans dentro del feminismo de cierta misoginia.
} 
Con la expresión "sujeto del feminismo" me refiero a una concepción o una comprensión del sujeto (femenino) como no solo distinto del de Mujer en mayúscula, la representación de una esencia inherente a todas las mujeres (que ha sido vista como Naturaleza, Madre, Misterio, Mal Encarnado, Objeto de Deseo [Masculino] y Conocimiento, Condición Femenina, Feminidad, etcétera), sino también algo distinto de las mujeres, lo real, seres históricos y sujetos sociales que son definidos por la tecnología del género y realmente engendrados en relaciones sociales. El sujeto del feminismo que tengo en mente es uno no tan definido, uno cuya definición o concepción está en proceso, en este y otros textos críticos feministas. (pp.9-10)

Podemos enlazar esta cita de De Lauretis con la teoría crítica de los derechos humanos y su historicidad que nos hablan de un ensanche de sujetos y luchas. Recordemos que el feminismo, junto con las reivindicaciones propias del sexo femenino se amplió a luchas antiesclavistas, raciales, infancia, derechos laborales, de liberación sexual, etc. entre otros colectivos. Ampliaron el propio sujeto del feminismo y incluyeron otros sujetos bajo la opresión sexogenérica y otras opresiones conexas.

Volver a reivindicar una biología excluyente por un lado y abogar por una destrucción de las identidades por otro, pueden ser estrategias muy peligrosas. Esto nos desvía de las estructuras a combatir: el heterocispatriarcado. A nuestro parecer es posible trabajar desde un feminismo focalizado en el sujeto mujer (biológica), junto a personas LGTBIQA+ e incluir posturas queer no binarias, no identitarias, no normativas que, al compartir la lucha contra el heterocispatriarcado opresor, sirvan para sumar esfuerzos, apoyos, sinergias y coherencia con otras identidades. El trabajo está en sumar identidades sin postergar otras, evitando que la construcción de categorías se convierta en una normativa excluyente, y que la homogeneización de sujetos cree relaciones de subordinación. Así es precisamente como ha operado el heterocispatriarcado.

Esta propuesta de feminismo jurídico queer se enlaza con los estudios tradicionales del feminismo jurídico, que señalan como los actores jurídicos no toman decisiones libres de sus creencias e ideología, el razonamiento jurídico está conectado con el político, las/ os jueces tienen en cuenta normas no jurídicas en sus decisiones, y los operadores jurídicos deberían ser sensibles a los hechos del mundo y las demandas sociales.

La historia de las mujeres, el estudio de sus particularidades y la identificación de sus discriminaciones, al igual que con el colectivo LGTBIQA+ y sexualidades no normativas, revela que la ley no se adecua a más realidades que las del varón hegemónico (blanco, heterosexual, cisgénero, cristiano, clase acomodada). En este sentido, lo no percibido, nombrado, tipificado o interpretado como una amenaza o una necesidad no lo es, ignorando, por ejemplo, la violencia contra las mujeres. Lo que no se piensa como una situación real, no tiene consecuencias reales para el agente jurídico, existiendo déficits en tipificación y aplicación legal.

Hasta ahora los feminismos han resquebrajado que las mujeres, las personas LGTBI$\mathrm{QA}+$, las sexualidades no normativas y todo lo tocante a ellas, como la violencia basada en género y la violencia sexual, queden fuera del tratamiento legal. Siguiendo a Segato (2003, p.27) hay una pervivencia del "residuo de la sociedad de estatus, premoderna, que ante- 
cede a la sociedad moderna y contractual constituida por sujetos sin marca (de género o raza) que entran en el derecho en un pie de igualdad."

Y cuando aparecen estas tendencias, lo hacen como una concesión "especial" o un tema "exclusivo" aparte de la figura del varón hegemónico: "El corpus legal sobre discriminación de género se entiende como un "asunto de mujeres", reforzando el entendimiento que el varón no tiene género, es una criatura estándar que no tiene que preocuparse por los asuntos de género" (Finley, 1989, p.888). El feminismo jurídico sospecha que el derecho y la justicia está transidos por los patrones heterocispatriarcales, de modo que invisibilizan todo lo que no se ajusta a este sistema de creación de conocimiento. En este sentido las mujeres, las personas LGTBIQA+ y las sexualidades no normativas quedan también fuera del tratamiento legal. Sólo aparecen para delimitarlos y criminalizarlos bajo la figura del varón hegemónico.

El proceso de creación, aplicación e interpretación de la norma está centrado en el varón, bajo el pretexto de la neutralidad que no es objetiva, sino parcial en su propio beneficio. A pesar de reconocer derechos de las mujeres y de las personas LGTBIQA+ y de tipificar determinados crímenes, que antes permanecían en la privacidad intocable para la justicia, como la violencia sexual, esta tendencia heterocispatriarcal sigue operando desde el punto de vista simbólico. Cambian las formas, pero la tendencia sigue funcionando bajo la capa de la universalidad de la ley y la abstracción de la igualdad. Aparentemente ya no es el derecho de varón hegemónico, pero sigue atrapado en sus propios marcos socioculturales. En palabras de Catharine MacKinnon (1995):

Las jerarquías entre los hombres se ordenan sobre la base de la raza y de la clase, estratificando también a las mujeres. El Estado toma esos hechos del poder social y los utiliza en la ley y como ley. Ocurren dos cosas: la ley se hace legítima y el dominio social se hace invisible. El legalismo liberal es, por tanto, un medio para hacer que el dominio masculino sea invisible y legítimo adoptando el punto de vista masculino e imponiendo al mismo tiempo esa visión a la sociedad. (pp. 427-428)

Con lo cual, el derecho sigue siendo otro ámbito del heterocispatriarcado, que legitima estos ideales jurídicos, intrínsecamente discriminatorios bajo la pretensión de universalidad e imparcialidad. Estos ideales, según Young (1990) sustentan al Estado neutral, mantienen los procesos jerárquicos de toma de decisiones y transforman el punto de vista de los grupos hegemónicos en universales.

Ya no es sólo una cuestión del texto normativo, que puede ser incluyente y no discriminatorio, sino de la interpretación de este y de la estructura y los mecanismos que siguen estando bajo un patrón heterocispatriarcal. Un ejemplo lo tenemos en la investigación de Susan Estrich sobre la violación sexual, demostrando que, a pesar de su penalización, los operadores jurídicos tienen ideas sobre las pruebas o las actitudes válidas que deben tener las mujeres. Esto lleva a la despenalización de las violaciones sexuales por parte de las personas conocidas o aquellas que se producen en citas (Jaramillo, 2009, p.122).

A veces, estas estructuras tienen la estrategia de situar a mujeres al frente de ellas o en departamentos de género. Esto se ve en el ámbito de la justicia, pero en palabras de 
Alda Facio (2000): "Es más fácil permitir la entrada de mujeres a las instituciones patriarcales que transformarlas. [...] es más fácil permitir que algunas mujeres lleguen a ser juezas de las cortes supremas que cuestionar los principios jerárquicos que organizan el sistema de administración de justicia" (p.18).

Aunque introducir nuevas voces y experiencias diversas en puestos de mando es muy positivo, hay dos problemas: introducir a una mujer, a una persona LGTBIQA+ o a una sexualidad no normativa no es sinónimo de que estas personas no sean misóginas u homófobas/transfóbicas. En segundo lugar, no sólo basta con introducir la diversidad y marcar cuotas de género en las instituciones, sino cambiar sus protocolos de actuación, que siguen siendo heterocispatriarcales.

Podríamos decir, haciendo una interpretación no sólo cultural y socioeconómica de reconocimiento, redistribución y representación según Nancy Fraser (2005), que la justicia puede llegar a reconocer estas identidades en base a un principio de igualdad, pero no redistribuye justicia desde lo económico, ni fomenta la representación en base a su diversidad desde lo político y yo añado lo estético, es decir el fomento de unos imaginarios inclusivos (Figura 2). Fraser (1997) afirma:

La ausencia de un proyecto emancipatorio amplio y creíble, a pesar de la proliferación de frentes de lucha; una escisión generalizada entre las políticas culturales de reconocimiento y las políticas sociales de redistribución, y el alejamiento de las pretensiones de igualdad frente a una agresiva mercantilización y un agudo crecimiento de las desigualdades materiales. (p.7)

Figura 2. Esferas de la justicia.
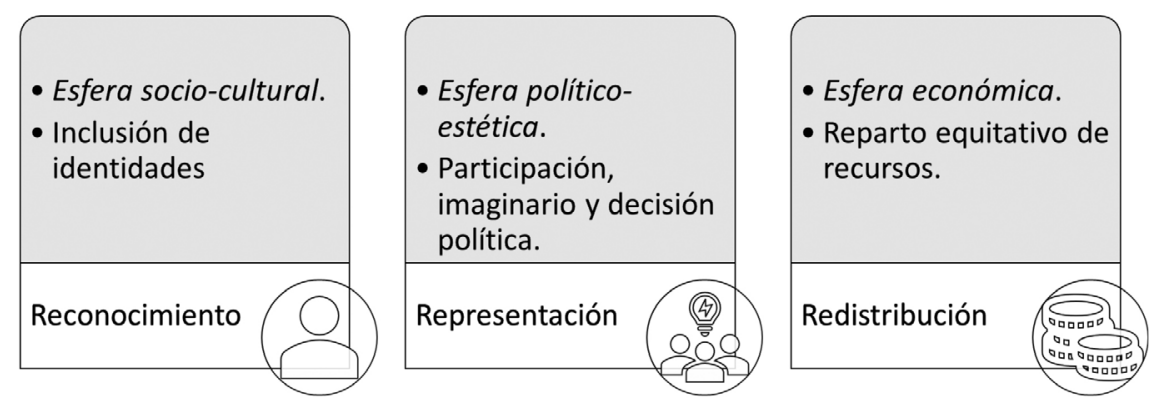

Fuente: elaboración propia y ampliada sobre Fraser (2005).

Se plantean problemas de la justicia que, más allá del texto normativo, no se aplica por igual. Gracias a este desenmascaramiento hay una progresiva inclusión de las identidades, expresiones y prácticas de género que chocan con las antiguas estructuras jurídicas, que podemos articular en tres momentos:

Sistema binario sexo/género: inclusión esencialista y binaria de las mujeres en tanto oposición a los varones que se ejemplifica en el reconocimiento de la igualdad y la prohibición de discriminación como principio fundamental. Esta línea va desde el feminismo liberal que propugna la igualdad legal, hasta otro más radical que defiende medidas de 
equidad, como pueden ser las cuotas de género, para favorecer el acceso de las mujeres al mercado laboral, por ejemplo. Como documentos más sobresalientes encontramos la Carta de las Naciones Unidas (1945), Declaración Universal de los Derechos Humanos (1948), Convención sobre los Derechos Políticos de la Mujer (1952), Pacto Internacional de los Derechos Civiles y Políticos (1966), Pacto Internacional de Derechos Económicos, Sociales y Culturales (1966). Y especialmente la Convención sobre la eliminación de todas las formas de discriminación contra la mujer (CEDAW, 1979), que tiene por objeto eliminar la discriminación contra las mujeres y asegurar la igualdad entre mujeres y varones. Esta Convención jurídicamente vinculante para los Estados signatarios, es revisada por un Comité que elabora Recomendaciones Generales aclaratorias de cada uno de sus párrafos. No será hasta la Recomendación General 23 (1997) cuando aparezca el concepto género de manera diferenciada al de sexo. Y será explicado desde la sociología en la Recomendación General 24 (1999). Por su lado, la aparición de las acciones positivas (equidad) no se verán hasta la Recomendación General 5 (1988) y más específicamente en la 25 (2004). Dentro del ámbito penal internacional destacamos el Tribunal Penal Internacional para Ruanda: Caso Akayesu (1998): testimonio de violencia sexual por parte de las mujeres, donde los abogados manifestaron que era: "de interés para psiquiatras, pero no para la justicia". Se admite finalmente el testimonio de las mujeres por el testimonio de un varón -el Comandante de la UNAMIR (Misión de Asistencia de las Naciones Unidas para Ruanda) Brent Beardsley-, la presión de los movimientos feministas y el interés particular de la jueza Navanethem Pillay.

Sistema binario de orientación sexual e identidad de género: unido al binarismo sexo/género, supone una inclusión y descriminalización de personas LGTBIQA+ con leyes antidiscriminatorias, matrimonio igualitario o leyes trans que reconocen el género y el sexo binario autopercibido. Este sistema y el siguiente no dejarán de ser polémicos, ya que cuestionan fuertemente cuál debe ser el sujeto principal del feminismo, como hemos visto. Los documentos fundamentales, aunque no jurídicamente vinculantes, son los Principios de Yogyakarta: Principios sobre la aplicación de la legislación internacional de derechos humanos en relación con la orientación sexual y la identidad de género (2006), reconoce la discriminación por motivo de orientación sexual e identidad de género y la protección de estas personas. Y la Declaración de la ONU sobre orientación sexual e identidad de género (2008), reivindica los derechos humanos de todas las personas más allá de su orientación sexual e identidad de género. Es de destacar la labor previa de la CEDAW por visibilizar estos términos en las Recomendaciones Generales 25 (2004), 27 (2010) o 28 (2010). Como mecanismo especial de protección y con gran polémica, en 2016 se creó la figura del Experto Independiente de Naciones Unidas para la protección contra la violencia y discriminación basadas en Orientación Sexual e Identidad de Género. Dentro de los crímenes de lesa humanidad: la primera persona del colectivo LGTBIQA+ es la querellante Valeria del Mar Ramírez por violencia sexual durante su detención ilegal en el centro clandestino de El Pozo de Banfield, en el periodo de la última dictadura argentina.

Sistema queer: basado en la teoría queer que aboga por la disolución de las categorías femenino y masculino, proponiendo no sólo la performatividad del género, sino también al sexo biológico y sexualidades como construcción social. Supone la desintegración 
del binarismo en una multitud identitaria e interseccional que, de esta manera, escapa de la opresión binaria que conlleva ser designado incorporando una pluralidad de identidades oprimidas. Este sistema aboga por un tratamiento diversificado y protegido de la diversidad afectivo-sexual, supone la protección de experiencias y prácticas no binarias, que son difíciles de regular. Algunos ejemplos pueden ser la creación administrativa de un tercer sexo o género neutro o las medidas de protección médica e identitaria para los bebés intersexuales. Algunos ejemplos nacionales pueden ser el Caso Norrie (2014) del Tribunal Supremo de Nueva Gales del Sur (Australia) que determinó la existencia de un género no definido $(\mathrm{X})$, además del varón $(\mathrm{XX})$ y de la mujer $(\mathrm{XY})$ teniendo presencia en documentos administrativos e identificativos. El reconocimiento por parte del Tribunal Supremo de la India en 2014 a las personas transexuales como un "tercer género" (hijras) diferente del femenino y del masculino. En 2017 la Corte Suprema alemana ha establecido que los bebés nacidos intersexuales tengan esta opción en el registro como tercer género. Y también ese mismo año Canadá da reconocimiento administrativo desde el nacimiento al "género desconocido". En el plano internacional, el Caso Bemba (2016) de la Corte Penal Internacional llevado por la jueza Sylvia Steiner opina que, respecto a la violencia sexual contra varones en la República Centroafricana, el cuerpo es entendido como neutro: "gender-neutral", algo que se puede interpretar desde lo queer. (Sánchez-Moreno, 2018).

Vemos como hay una evolución inclusiva, en base a unos referentes teóricos y unos reclamos, con visión de futuro, pero en base a una experiencia del pasado. Como veíamos hay una crítica al universalismo de los derechos humanos que se considera poco práctico, poco efectivo. Por esta razón, y en base a los movimientos sociales, se elabora una teoría crítica de los derechos humanos que los ve como resultado de las luchas sociales y como un producto cultural y colectivo, que es justamente lo que hace que el lema feminista radical "lo personal es político" alcance todo su sentido de contra-poder como ley del más débil (Ferrajoli, 1999, p.54).

\section{Forclusión, abyección y repugnancia}

Pero podemos ir más allá e intentar ir a las causas que frenan esta evolución inclusiva en el derecho. Debemos esclarecer que en este uso sesgado del derecho opera el fundacionalismo que consiste en el uso de ciertas creencias establecidas hegemónicamente desde la fuerza, sobre las que se fundan nuevas creencias o conocimientos. Esta imposición hegemónica proporciona una presunta neutralidad y objetividad del derecho (Balkin y Levinson, 2008, p.211). Las leyes y su interpretación vienen de personas superiores cuyo conocimiento es incuestionable -son varones o aplican este patrón- y al que no tenemos acceso.

Las creencias impuestas e incuestionables del fundacionalismo son la base de la forclusión, término psicoanalítico: algo/alguien que se ha repudiado de lo Simbólico y que reaparece en lo Real (Spivak, 2010, p.17). Es el rechazo simbólico de un sujeto y un significante, que no aparece inscrito en el subconsciente. Un sujeto expulsado y excluido de la realidad, pero invisibilizado ante esta situación por la exclusión simbólica que tiene. 
La "forclusión" opera a través de la negación del sujeto y significante y de desmentir esta negación, con lo cual la invisibilización queda oculta y la discriminación "legitimada".

Para Butler esta "forclusión" no es inconsciente sino social e histórica, consintiendo relaciones de poder que subliman determinadas identidades para mantener su hegemonía. Esta forma de pensar y nombrar -u ocultar-, está inserta en nuestra educación y prácticas culturales y condiciona nuestra percepción de la realidad. Podemos decir que cada sujeto no habla, sino que es hablado (Lacan, 2003, p.269) por unas cosmovisiones e ideologías universales (razón fundacional) (Butler, 2004, p.41) que interpretan el mundo y lo gestionan desde esta "forclusión". Su extremo serían los integrismos religiosos y los totalitarismos políticos.

Hay otros conceptos, algunos de los cuales veremos más adelante que van en este sentido, como la abyección (Kristeva, 2004), la repugnancia y vergüenza (Nussbaum, 2006), la preterición o la preterización que resumimos en la Tabla 1.

Tabla 1. Conocimientos naturalizados y "neutrales"

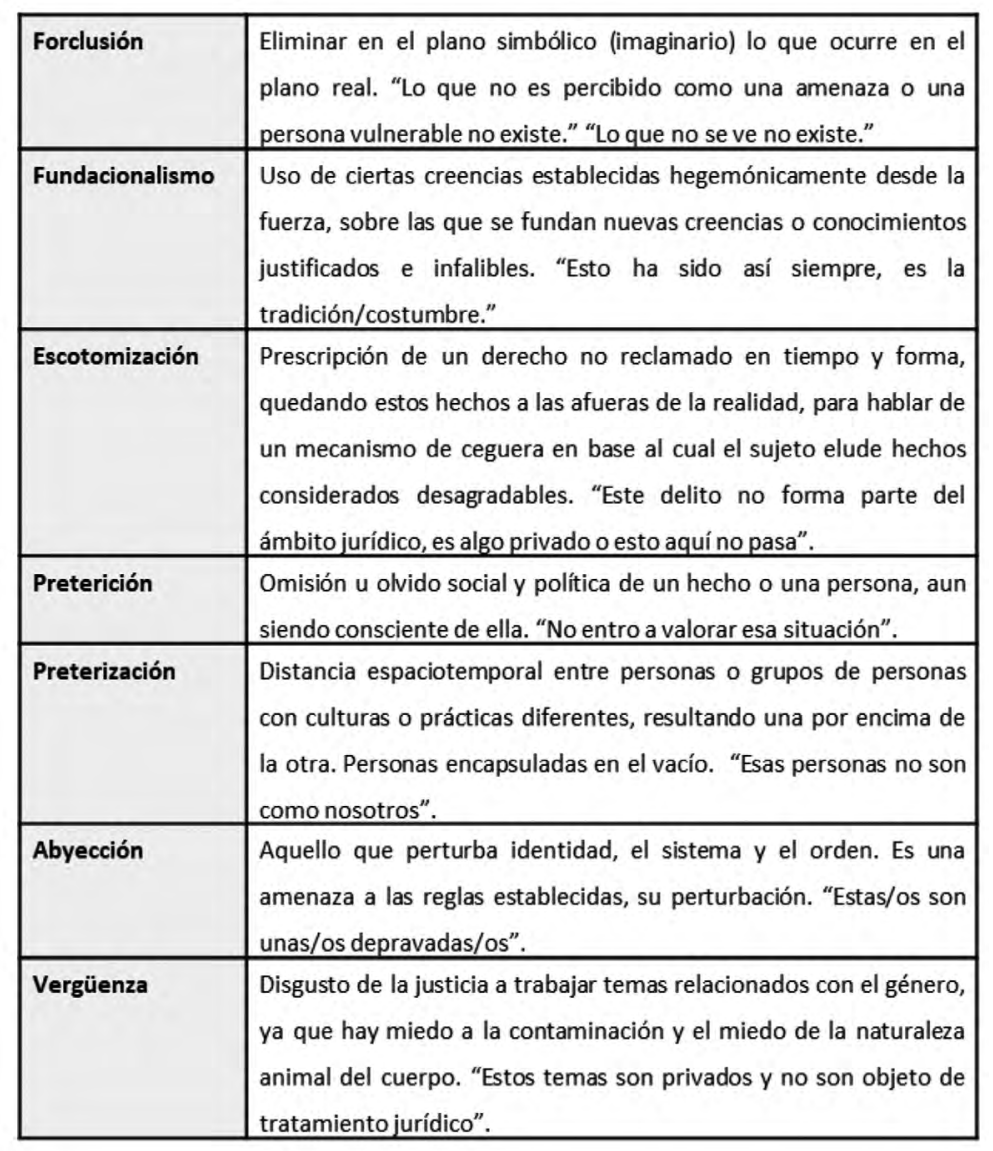

Fuente: elaboración propia.

El resultado es una exclusión pasiva, sin esfuerzo y sin consciencia de excluir, ya que se basa en un orden de las cosas "natural", "universal" e "histórico" sobre el que se han construido los regímenes políticos y jurídicos de ciudadanía, por ejemplo. Solo recupera su consciencia y reduplica su violencia cuando las personas excluidas se quejan respecto 
a su situación y son capaces de vaciar los conceptos a través de los que "son hablados", resignificarlos o construir unos nuevos, superando el orden simbólico de la "forclusión" para avanzar hacia lo real (Zizek, 2008). Se puede decir que la forclusión es el germen de la construcción de la otredad, siendo los sujetos excluidos más perfectos las mujeres, las personas LGTBIQA+ y las sexualidades no normativas. Son sujetos deshumanizados ya que no tienen características valorables como para ser considerados como tales.

Se crean identidades subyugadas que pertenecen a cuerpos excluidos. Si seguimos a Foucault (2007), vemos que hay cuerpos que importan y cuerpos que no. Cuerpos sometidos a una biopolítica, una tecnología del poder sobre determinados individuos y cuerpos, que se ven disciplinados ${ }^{8}$. Cuerpos que importan y cuerpos que no importan, que no merecen la pena ser reclamados ni llorados en una ausencia de empatía y corresponsabilidad (Butler, 2006), ignorados por una justicia deshumanizada. Parece que se niega el derecho al duelo y a la vulnerabilidad de los cuerpos mediante discursos deshumanizadores.

Según Martha C. Nussbaum (2010) esto responde a unas "políticas de la repugnancia". Argumenta que el disgusto de la justicia a trabajar temas relacionados con la homosexualidad reside en la ansiedad por la contaminación y el miedo de la naturaleza animal del cuerpo. De este modo se imagina el cuerpo y el ser sexualmente no normativo como susceptible de enfermedades, lleno de substancias y con un uso desordenado. Es el miedo a ser manchado por temas que nos recuerdan la animalidad, la mortalidad, la naturaleza corporal. Al igual que ocurre con el cuerpo de las mujeres. De este modo el individuo se posiciona en una heterosexualidad falocéntrica ${ }^{9}$. Todo lo que queda fuera y amenaza su hegemonía es duramente relegado a la categoría de sujetos abyectos en el sentido que le da Kristeva (2004). La heterocisexualidad organiza y resignifica cuerpos e identidades en su papel no de opción sexual sino de régimen de poder basado en el binomio jerárquico varón/mujer, excluyendo a todo lo demás (Butler, 2005, pp.19-20).

A la repugnancia se suma la vergüenza en el tratamiento jurídico, que inculca una humillación especial a los temas de violencia sexual, conciliación, matrimonio igualitario, etc. como asuntos privados, domésticos y despolitizados (Nussbaum, 2006). Para Nussbaum esto está presente en el racismo, en el antisemitismo, la misoginia, la homofobia o la transfobia. De alguna manera se siguen considerando grupos incivilizados, no son personas completas, por ello son más animales y corporales que personas con capacidad de raciocinio, facultad exclusiva del varón normativo. Esto no sólo se puede extender a determinados colectivos, sino a determinados temas, como es la sexualidad que se usa para denegar el acceso a la justicia a mujeres, a personas LGTBIQA+ y como aquí proponemos a las sexualidades no normativas. Son sujetos y temas no sólo relegados por la privacidad, sino también por la repugnancia y por la vergüenza, los tres factores intocables hasta hace poco por la justicia (Nussbaum, 1999, p.15).

\footnotetext{
${ }^{8}$ Aunque las teorías del poder de Foucault son valiosas, ha habido cierta fricción entre los feminismos y el postestructuralismo, al cuestionar los sujetos oprimidos y obviar al patriarcado. Ver Boyer, 2012.

${ }^{9}$ Concepto de Judith Butler que explica cómo la heterosexualidad implica asumir un sexo determinado. Tiene sus antecedentes en la "heterosexualidad obligatoria" acuñado por Adrienne Rich, describe una institución política que sostiene al patriarcado. También está en relación el concepto "heteronormatividad" de Michael Warner, que presenta la heterosexualidad como un régimen impuesto en varios ámbitos de la vida (sociales, culturales, políticos, económicos, etc.).
} 
La concreción de todo esto es la conformación del prejuicio, que según el Diccionario de la Academia de la Lengua es la "opinión previa y tenaz, por lo general desfavorable, acerca de algo que se conoce mal". Y prejuiciar: "predisponer a una persona en contra de alguien o de algo." No hay que individualizar prejuicio sólo en la figura de una persona, sino como un síntoma social. El prejuicio se basa en un estereotipo, que según el mismo diccionario es una "imagen o idea aceptada comúnmente por un grupo o sociedad con carácter inmutable". Una idea que generalmente es negativa y que se considera nociva para la sociedad y la construcción del Estado.

Esta concepción de los cuerpos hace que las violencias se oculten, particularmente la violencia sexual en tres patrones: la que se produce contra mujeres y niñas, la que se produce contra varones y niños (con una finalidad de feminizar y homosexualizar), y la que se produce contra personas LGTBIQA+ y sexualidades no normativas. Todas deficientemente visibilizadas, especialmente las dos últimas por el tabú la homosexualidad, tienen como objeto someter a los cuerpos y mantener el orden heterocispatriarcal (SánchezMoreno, 2018). Estas dinámicas posibilitan no solo la invisibilización sino el menosprecio, maltrato y destrucción de estos cuerpos (Honneth, 1985; Scarry, 1985).

Frente a esto Nussbaum propone unas "políticas de la humanidad", basadas en la capacidad para imaginar y empatizar con las personas "otras" como seres humanos como los demás, merecedores del mismo tratamiento y respeto ante la ley. Es decir, personas titulares de plenos derechos. Este sería un ejercicio de superación para superar en la justicia las anteriores emociones, que responden al orden heterocispatriarcal.

En este sentido propone que los sistemas educativos vuelvan a las humanidades (desarrollo humano), incluyendo el valor de la historia, la filosofía, los feminismos y las luchas sociales para la construcción democrática y ciudadana, frente a la tecnificación y productividad educativa, orientada al modelo productivo (desarrollo económico). Una educación humana hace desarrollar la empatía y compasión entre los seres humanos; promover un pensamiento crítico para construir nuevos escenarios consensuados; y entenderse como parte del mundo que comparte problemas y soluciones (Nussbaum, 2010). En nuestro campo, esto se traduce en una formación en las facultades de derecho y a los operadores jurídicos para que contemplen este bagaje en la redacción de textos normativos y su aplicación jurisprudencial.

\section{Las dimensiones del sexismo}

Las mencionadas políticas de la repugnancia operadas por el heterocispatriarcado generan una discriminación basada en el sexo que tiene manifestaciones concretas sobre las mujeres, sobre las personas LGTBIQA+ y sobre las sexualidades no normativas (siguiendo lo queer). Estas dos últimas las recogemos bajo el concepto de diversidad afectivo-sexual. Reelaborando y abriendo la propuesta de Margrit Eichler (1991) a la citada diversidad, presentamos las siguientes dimensiones del sexismo (Figura 3): 
Figura 3. Manifestaciones del sexismo.

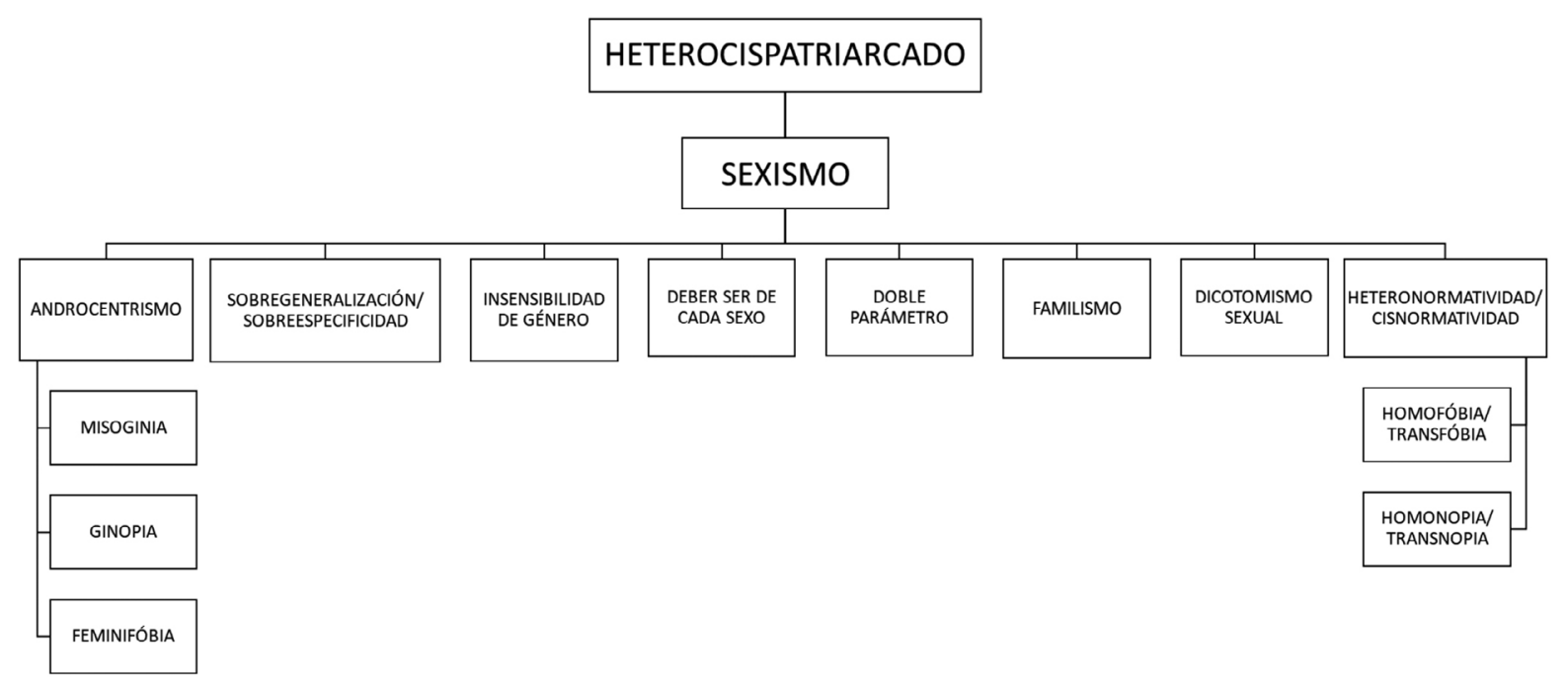

Fuente: elaboración propia y ampliada sobre Eichler (1991).

Dicotomismo sexual: consiste en tratar a los sexos como diametralmente opuestos y no con características semejantes. Esta dicotomía también se puede aplicar a la orientación sexual e identidad de género. Hasta tal punto que todas ellas ocupan todas las esferas en las que vemos a las personas. En este sentido una mujer es esencialmente una mujer con sus roles estereotipados y diferentes en todo a un varón, y un homosexual una persona que mantiene relaciones sexuales (raramente afectivas) con personas de su mismo sexo, y que no tiene nada que ver con una persona heterosexual. La orientación sexual/ identidad de género se esencializa y no se ve como un aspecto más de la personalidad, sino determinante hacia comportamientos reprobables. Las personas trans son raras y a evitar y no se contempla nada más allá de esta dicotomía y las prácticas asociadas a ella.

Deber ser de cada sexo: estereotipos marcados para cada sexo, basados en la creencia de que hay conductas o características humanas que son más apropiadas para un sexo que para el otro. En ellas una manera específica de ser heterosexual para cada sexo y de mostrar feminidad las mujeres, así como masculinidad los varones. Esto conlleva el desprecio, por ejemplo, de las mujeres lesbianas, que muestran actitudes o expresiones tradicionalmente consideradas masculinas. También miedo o extrañeza hacia la mezcla de ambos sexos o la negación de los mismos.

Doble parámetro: similar a lo que conocemos como doble moral. Se da cuando la misma conducta, situación idéntica o característica humana, es valorada con distintos parámetros o instrumentos para cada sexo, que impone al género una serie de roles impermeables entre sí. Ocurre igual con personas no heterosexuales/no cisgénero/ no normativas, a las que no se admiten determinadas acciones consagradas al resto, como el matrimonio o la filiación.

Familismo: mujer y familia son sinónimos y comparten necesidades e intereses. Está asentado en la función reproductora de la mujer y en la distribución sexista del 
trabajo que atribuye a la mujer el rol de cuidado familiar. Esta mujer madre y cuidadora de la familia está por encima de la mujer como persona, con otras funciones e intereses, como los del trabajo fuera de casa, los de no contemplar su función reproductora o ser lesbiana. A su vez, se reprueban otras formas de familia: monoparentales, entre dos gays, dos lesbianas, etc.

Insensibilidad de género: ocurre cuando se ignora la categoría de género como una variable socialmente importante y legítima, es decir, cuando no se toman en cuenta los distintos lugares que ocupan las mujeres y los varones en su diversidad de identidades, prácticas, expresiones y situaciones en la estructura social (aunque estas sean no normativas), a favor del varón heterosexual y cisgénero estereotipado.

Sobregeneralización y sobreespecificidad: la sobregeneralización ocurre cuando un estudio, teoría o texto sólo analiza la conducta del varón heterosexual cisgénero, pero presenta los resultados del análisis o el mensaje como válidos para ambos sexos y toda la diversidad afectivo-sexual. La sobreespecificidad presenta como específico de un sexo y orientación sexual/identidad de género ciertas necesidades, actitudes e intereses que en realidad son de ambos sexos y de la diversidad afectivo-sexual.

Androcentrismo: es la manifestación del sexismo heterocispatriarcal más evidente que sucede cuando un comportamiento, estudio, análisis o investigación se enfoca sólo desde la perspectiva masculina, presentando esta experiencia como central a la experiencia humana y por lo tanto como la única relevante. El androcentrismo tiene tres formas extremas de manifestarse: la misoginia como el repudio a las mujeres, la ginopia como la invisibilización de la experiencia de las mujeres, y la feminifobia como el rechazo a lo femenino y no normativo. Esta última fobia está también presente cuando se desprecian a varones con ademanes femeninos o "pluma", a personas trans o cuando se ve la ausencia femenina como un valor.

Heteronormativismo y cisnorma: es la normalización y naturalización de la sexualidad y afectos de las relaciones heterosexuales y la identidad de género correspondiente con el sexo biológico, que rechazan cualquier tipo de diversidad afectivo-sexual. Tiene dos formas extremas de manifestarse: la homofobia/transfobia como el repudio a las personas LGTBIQA+ y a lo relativo a ellas, y la homonopia/transnopia como la invisibilización de la experiencia de las personas LGTBIQA+ o lo relativo a las prácticas asociadas a las sexualidades no normativas, cuando se contempla el no binarismo como un error.

Vemos que mujeres, personas LGTBIQA+ y no binarias comparten la misma raíz discriminatoria y opresiva. Si sumamos estas manifestaciones del sexismo a lo visto en el anterior epígrafe podemos construir una violencia piramidal (Figura 4). La violencia es un mecanismo para mantener las jerarquías sociales que aquí hemos analizado y proteger el heterocispatriarcado. Generalmente este tipo de violencias se han llegado a tipificar en los códigos penales como violencia de género, violencia doméstica, violencia contra la mujer, femicidio, feminicidio, transfeminicidios, discurso de odio y crimen de odio, cuyo análisis excede los objetivos de este artículo. 
Figura 4. Causas y efectos de la violencia.

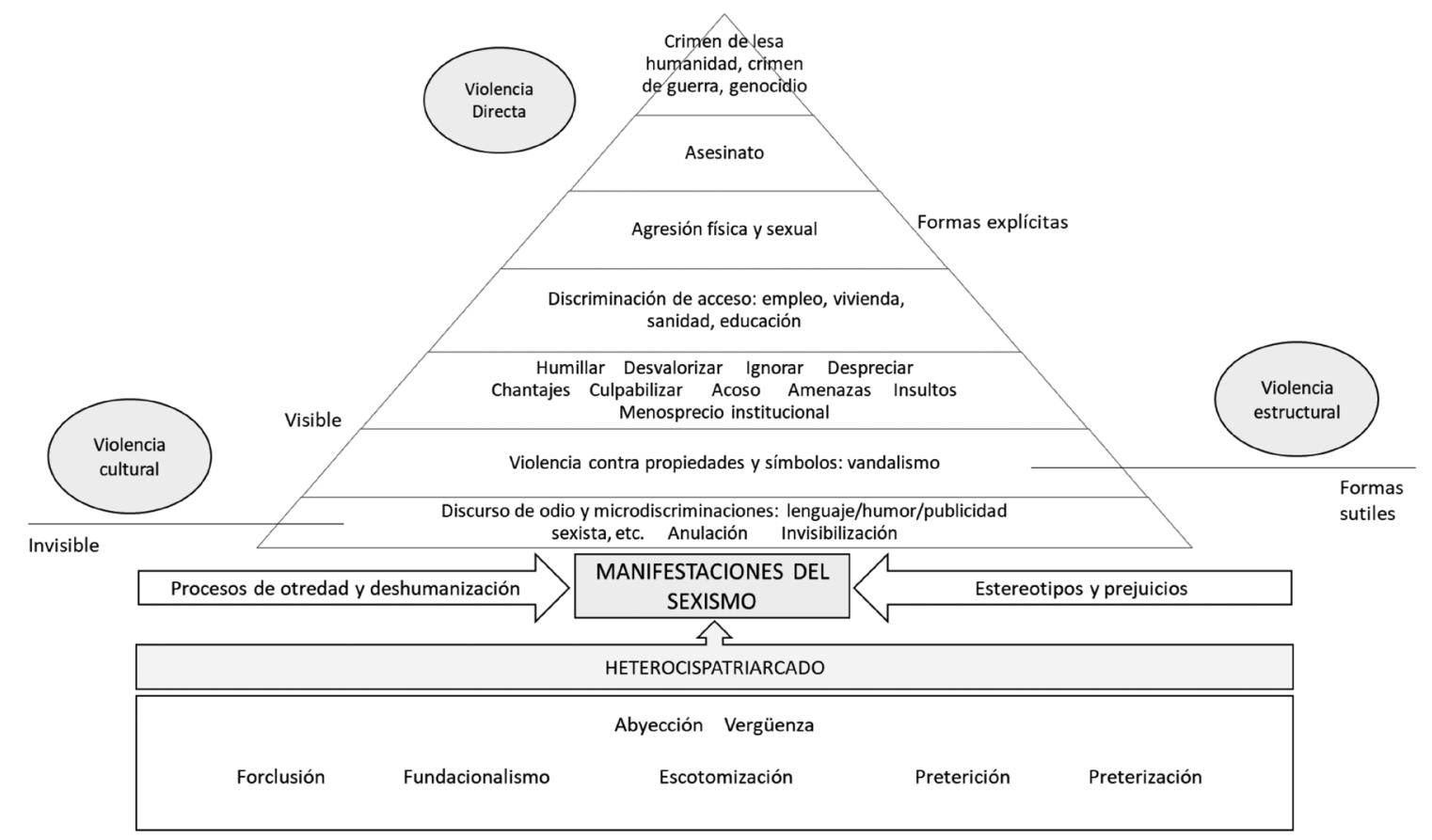

Fuente: elaboración propia y ampliada sobre Eichler (1991).

Estas violencias se basan en tres ejes (Galtung, 2003): violencia cultural como legitimación de los comportamientos violentos desde la familia, la escuela, la religión, el Estado. La violencia estructural que son las estructuras físicas y organizativas que impiden la satisfacción de necesidades básicas como el bienestar, la identidad, el ejercicio de la libertad, el disfrute de derechos o el acceso a la justicia. Y finalmente violencia directa son los comportamientos más visibles que se fundamentan en la violencia estructural y en la cultural. Los delitos van desde los micromachismos hasta el asesinato o los crímenes internacionales, de manifestaciones más o menos visibles a otras más o menos explícitas.

Todo esto se mantiene desde una sociedad heterocispatriarcal que crea unos estereotipos y prejuicios como hemos visto, fundamentados en unos procesos de otredad (de exclusión) y de deshumanización.

\section{Propuesta metodológica}

Uniendo mujeres, personas LGTBIQA+ y sexualidades no normativas, o lo que aquí mencionamos como mujeres y diversidad afectivo-sexual vamos a proponer una metodología desde el feminismo jurídico queer, teniendo en cuenta el desarrollo teórico que hemos venido exponiendo. Esto no deja de ser algo arriesgado. Corremos el riesgo de ser calificadas como poco neutrales, pero ¿por qué hasta ahora lo neutral y objetivo (lo científicamente válido) está sesgado por la referencia y hegemonía de una masculinidad excluyente? ¿Es más objetivo un método que invisibiliza a parte de la humanidad que otro 
dedicado a cambiar los puntos de vista para lograr un gran angular? (Sanchis, 2012; Sanchis, 2015) Donna Haraway (1995), en su teoría de los conocimientos situados cuestiona el punto de vista desde el que se analizan las cosas, ya que más allá de la metodología empleada, el contexto no suele ser neutral sino heterocispatriarcal.

Una de las mayores aportaciones a la metodología feminista lo dio Sandra Harding (1987; 1996) que distingue entre método, metodología y epistemología. El método son las técnicas de recopilación de información. La metodología es el procedimiento de investigación. Y la epistemología bien podría ser la teoría de los conocimientos situados de Haraway, es decir el lugar hermenéutico que usamos para nuestro análisis.

En metodología destacamos la propuesta de Alda Facio (1993), en base a siete puntos que reelaboramos y reordenamos en torno a tres esferas e incluyendo la interseccionalidad y el análisis del sexismo. Mediante estos pasos se puede analizar el fenómeno jurídico, para identificar el sesgo heterocispatriarcal (figura 5):

Figura 5. Metodología jurídica feminista queer.

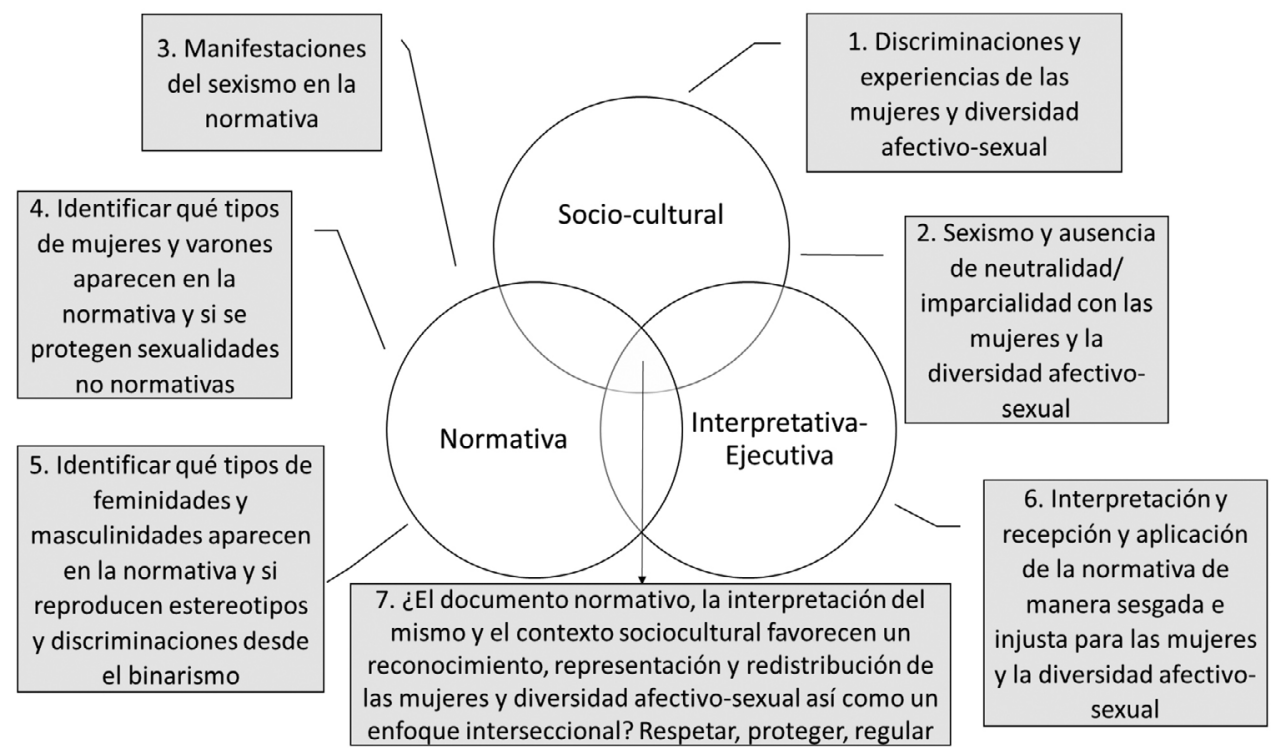

Fuente: elaboración propia.

Esfera socio-cultural: son los marcos culturales y sociales, las cosmovisiones que producen los textos legales, su recepción e impacto social.

1. Considerar las discriminaciones basadas en género y diversidad afectivo-sexual. Para ello se deben analizar las experiencias de mujeres, de las personas LGTBI$\mathrm{QA}+\mathrm{y}$ de las personas no normativas, así como de las estructuras y dispositivos discriminatorios que disciplinan y sus resistencias sociales, bajo el paradigma de la multidimensionalidad.

2. Considerar el sexismo como fuente de discriminación, al pretender neutralidad en instituciones y documentos que responden al patrón del varón heterocisexual y su experiencia, excluyendo otras posibles. 
Esfera normativa: es la literatura normativa, el texto en sí que, siguiendo a Benjamin es un documento de cultura y a la vez de barbarie.

3. Identificar las distintas formas en que se manifiesta el sexismo en documentos normativos y jurisprudenciales, que terminan por excluir, invisibilizar o subordinar. Aquí se irá de lo general a lo concreto, es decir: norma internacional, norma regional y norma nacional, y dentro de esta última considerando el texto constitucional o leyes fundamentales en primer lugar y las emanadas de éstas.

4. Identificar qué tipo de mujer y de varón aparecen en la jurisprudencia: etnia, orientación sexual, identidad de género, clase y otros para ver qué estereotipos de mujeres y varones proponen y si estos pueden ser perjudiciales para sexualidades no normativas. Si bien el varón no representa a toda la humanidad, tampoco lo hace un solo tipo de mujer, como tampoco el binarismo femineidad-masculinidad.

5. Identificar qué tipo de masculinidades y femineidades propone la norma y la jurisprudencia para encontrar soluciones a la exclusión: mujer-madre, varóntrabajador, mujer-familia, varón-soldado, homosexual-enferma, transexual-criminal, persona no binaria por poner unos ejemplos. Ver si los tipos de mujeres y diversidad afectivo-sexual se trabajan como un componente aparte del resto del texto que seguiría estando centrado en el varón normativo, o si aparecen transversalmente.

Esfera interpretativa-ejecutiva: jurisprudencia, opiniones, interpretaciones, protocolos, políticas públicas y procedimientos mediante los cuales las instituciones jurídicas implementan el texto legal y las instituciones lo ejecutan.

6. Considerar la influencia y los efectos respecto a otros componentes del fenómeno legal, cosmovisiones, vinculadas con el contexto o con la interpretación de juezas y jueces y las/os tomadoras/es de decisiones. También los poderes fácticos que pueden intervenir o legitimar, como la religión.

Finalmente, y con un carácter transversal, añado un séptimo paso que analice si el documento normativo, la interpretación del mismo y el contexto sociocultural favorece un reconocimiento, representación y/o redistribución de las mujeres y la diversidad afectivosexual con enfoque interseccional. Se debe valorar el respeto, la protección y la regulación. Respeto y protección para mujeres, personas LGTBIQA+ y sexualidades no normativas; y regulación para mujeres y personas LGTBIQA+. Este paso es clave ya que va más allá de evidenciar los sesgos de un documento, para avanzar en la localización de las injusticias y poner un primer pilar de cara a solucionar estas problemáticas.

Esta es una metodología que aquí aplicamos al ámbito jurídico pero que se puede amoldar a cualquier otro ámbito, estructura y texto. 


\section{Conclusiones}

1. El género como roles construidos, estereotipados y de sometimiento de los varones sobre las mujeres, incluye a la diversidad afectivo-sexual, entendida como personas LGTBIQA+ y sexualidades no normativa y no binaria.

2. El principio de universalidad y el derecho a la igualdad consagrados en la Declaración Universal de los Derechos Humanos (1948) se interpretan bajo patrones heterocispatriarcales y excluyentes.

3. El fundacionalismo y el fenómeno sociológico de la forclusión como doble ocultación real y simbólica de las mujeres y la diversidad afectivo-sexual sigue operando en las estructuras estatales y jurídicas.

4. La ley y su interpretación se construye en base a las experiencias del varón normativo, desechando el género como un elemento propio de las mujeres que, en el mejor de los casos requiere un tratamiento especial y en absoluto transversal o estandarizado en la construcción del fenómeno jurídico.

5. La introducción teórica y vivencial de las mujeres y la diversidad afectivo-sexual se debe gracias a la incidencia de la academia y de grupos feministas y de liberación LGTBIQA+, con reflexión de la teoría queer en foros internacionales y en el plano nacional.

6. Los feminismos, los movimientos LGTBIQA+ y la teoría queer se enfrentan al heterocispatriarcado de la ley desde dos posturas, incluyendo a las mujeres en el universalismo y la igualdad o proponiendo la diferencia de todas las personas en unas identidades queer que quieren escapar del binarismo sexual, porque consideran que ahí radica la trampa de la opresión.

7. Hay un disgusto de la justicia para trabajar cuestiones de género, al considerarlas cuestionables, no neutrales o privadas, cuando no asuntos abyectos ajenos al equidistante ejercicio legal.

8. La neutralidad e imparcialidad de la ley es una falacia que oculta patrones heterocispatriarcales, razón por la cual se debe recuperar la empatía, la humanidad y las ciencias sociales para construir, interpretar, modificar y analizar la normativa.

9. La interseccionalidad y el análisis multidimensional son fundamentales para identificar el heterocispatriarcado presente en el derecho.

10. El sexismo afecta tanto a las mujeres como a la diversidad afectivo-sexual, e impone diversos tipos de violencias presentes explícita o implícitamente en los textos normativos.

\section{Bibliografía}

ALCOFF, LINDA (1988). Cultural feminism versus post-structuralism: The identity crisis in feminist theory. Signs, 13(3), 405-436. 
AMORÓS, CELIA (1991): Partidos políticos y movimientos sociales. Cuadernos de Ciencias Sociales, 40.

ARENDT, HANNAH (2004). Los orígenes del totalitarismo. México D.F.: Taurus.

ARRIOLA, ELVIA R. (1994). Gendered Inequality: Lesbians, Gays, and Feminist Legal Theory. Berkeley Women's Law Journal, 9, 103-143.

BALKIN, JACK M. y LEVINSON, STANFORD (2008). El derecho y las humanidades: una relación incómoda. Revista Jurídica de la Universidad de Palermo, 9(1), 197-228.

BENHABIB, SEYLA (2006). El ser y el otro en la ética contemporánea. Feminismo, comunitarismo y posmodernidad. Barcelona: Gedisa.

BENJAMIN, WALTER (1973). Discursos interrumpidos, I. Madrid: Taurus.

BOBBIO, NORBERTO (1990). L'étá dei diritti. Turín: Einaudi.

BOWLEG, LISA (2008). When Black + Lesbian + Woman $\neq$ Black Lesbian Woman: The Methodological Challenges of Qualitative and Quantitative Intersectionality Research. Sex Roles, 59, 312-325.

BOYER, AMALIA (2012). Biopolítica y filosofía feminista. Revista de Estudios Sociales, 43, 131-138.

BUTLER, JUDITH (2004). Universalidades en competencia. En JUDITH BUTLER, ERNESTO LACLAU y SLAVOJ ZIZEK, Contingencia, hegemonía y universalidad. Diálogos contemporáneos en la izquierda (pp. 141-184). Buenos Aires: Fondo de Cultura Económica).

BUTLER, JUDITH (2005). Cuerpos que importan. Sobre los límites materiales y discursivos del sexo. Buenos Aires: Paidós.

BUTLER, JUDITH (2006). Vida precaria. El poder del duelo y la violencia. Buenos Aires: Paidós.

BUTLER, JUDITH (2007). El género en disputa. El feminismo y la subversión de la identidad. Barcelona: Paidós.

COMANDUCCI, PAOLO (2000). Derechos humanos y minorías: un acercamiento analítico neoilustrado. En MIGUEL CARBONELL (Comp.), Derechos sociales y derechos de las minorías (pp. 21-42). México: Instituto de Investigaciones Jurídicas de la UNAM.

CRENSHAW, KIMBERLÉ (1989). Demarginalizing the Intersection of Race and Sex: A Blak Feminist Critique of Antidiscrimination Doctrine, Feminist Theory and Antiracist Politics. University of Chicago Legal Forum, 1989(1), 139-167.

CRENSHAW, KIMBERLÉ (1993). Beyond Racism and Misogyny: Black Feminism and 2 Live Crew. En Mari J. MATSUDA et al. (Ed.), Words That Wound: Critical Race Theory, Assaultive Speech, and the First Amendment (pp. 246-263). Colorado: Westview Press.

DE LAURETIS, TERESA (1987). Technologies of Gender. Essays on Theory, Film, and Fiction. London: MacMillan.

DE LAURETIS, TERESA (1991). Queer Theory: Lesbian and Gay Sexualities. An Introduction. differences: a Journal of Feminist Cultural Studies, 3(2), iii-xviii.

DE LAURETIS, TERESA (1994). Habit Changes. differences: A Journal of Feminist Cultural Studies, 6(2-3): 296-313.

EICHLER, MARGRIT (1991). Nonsexist Research Methods: A Practical Guide. New York: Routledge. 
FACIO, ALDA (1993). Cuando el género suena, cambios trae. Una metodología para el análisis del fenómeno jurídico desde la perspectiva de género. Costa Rica: ILANUD.

FACIO, ALDA (2000). Hacia otra teoría crítica del derecho. En GIOCONDA HERRERA (Coord.), Las fisuras del patriarcado, Reflexiones sobre Feminismo y Derecho (pp. 1544). Quito: FLACSO.

FERRAJOLI, LUIGI (1999). Derechos y garantías. La ley del más débil. Madrid: Trotta.

FINLEY, LUCINDA M. (1989). Breaking Women's Silence in Law: The Dilemma of the Gendered Nature of Legal Reasoning. Notre Dame Law Review, 64, 889-910.

FISCHEL, JOSEPH (ed.) (2019). Critical Analysis of Law. Special Issue: Queer Legal Studies, 6(1). Recuperado de https://cal.library.utoronto.ca/index.php/cal/issue/view/2210

FOUCAULT, MICHEL (2007). Nacimiento de la biopolítica. Curso en el Collège de France (1978-1979). México: Fondo de Cultura Económica.

FRASER, NANCY (1997). Iustitia Interrupta. Reflexiones críticas desde la posición "postsocialista". Bogotá: Siglo del Hombre Editores/Universidad de los Andes.

FRASER, NANCY (2005). Mapping the feminist imagination: from redistribution to recognition to representation. Constellations, 12(3), 295-307.

GALTUNG, JOHAN (2003). Tras la violencia, 3R: reconstrucción, reconciliación, resolución. Afrontando los efectos visibles e invisibles de la guerra y la violencia. Gernika: Bakeaz/ Gernika Gogoratuz.

GARCÍA PRINCE, EVANGELINA (2016). Políticas de Igualdad, Equidad y Gender Mainstreaming. ¿De qué estamos hablando? Marco Conceptual. Recuperado de http://www.americalatinagenera.org/es/documentos/doc_732_Politicasdeigualdad23junio08.pdf

HARAWAY, DONNA (1995). Ciencia, cyborgs y mujeres: la reinvención de la naturaleza. Madrid: Ediciones Cátedra.

HARDING, SANDRA (1987). Introduction: Is There a Feminist Method? En SANDRA HARDING (Ed.), Feminism and methodology: social science issues (pp. 1-14). Bloomington: Indiana University Press.

HARDING, SANDRA (1996). Ciencia y Feminismo. Madrid: Ediciones Morata.

HERRERA FLORES, JOAQUÍN (2007). La reinvención de los derechos humanos. Sevilla: Atrapasueños.

HILL COLLINS, PATRICIA (1990). Black Feminist Thought: Knowledge, Consciousness, and the Politics of Empowerment. Boston: Unwin Hyman.

HONNETH, AXEL (1985). The Struggle for Recognition: The Moral Grammar of Social Conflicts. Cambridge: MIT Press.

HUTCHINSON, DARREN LENARD (1999). Ignoring the Sexualization of Race: Heteronormativity. Buffalo Law Review, 47(1), 1-116.

JARAMILLO, ISABEL CRISTINA (2009). La crítica feminista al derecho. En RAMIRO ÁVILA SANTAMARIA, JUDITH SALGADO y LOLA VALLADARES (Comp.), El género en el derecho. Ensayos críticos (pp. 195-223). Quito, Ministerio de Justicia y Derechos Humanos/Unifem/Naciones Unidas.

JOHNSON, REBECCA (2005). Gender, Race, Class and Sexual Orientation: Theorizing the Intersections. En GAYLE MACDONALD, RACHEL L. OSBORNE y CHARLES C. SMITH 
(Eds.), Feminism, Law, Inclusion: Intersectionality in Action (pp. 21-37). Toronto: Sumach Press.

KEMELMAJER, Aída (2001). Las acciones positivas. Jueces para la democracia, 41, 49-69. Recuperado de https://dialnet.unirioja.es/descarga/articulo/174857.pdf

KRISTEVA, JULIA (2004). Poderes de la perversión. México: Siglo XXI Editores.

KWAN, PETER (1997). Intersections of Race, Ethnicity, Class, Gender \& Sexual Orientation: Jeffrey Dahmer and the Cosynthesis of Categories. Hastings Law Journal, 48, 1257-1264.

KWAN, PETER (2000). Complicity and Complexity: Cosynthesis and Praxis. DePaul Law Review, 49, 673-687.

LACAN, JACQUES (2003). Símbolo y lenguaje como estructura y límite del lenguaje psicoanalítico. En JACQUES LACAN, Escritos I (pp. 255-278). Buenos Aires: Siglo XXI Editores.

MACKINNON, CATHARINE (1995). Hacia una teoría feminista del Estado. Madrid: Ed. Cátedra.

MAKKONEN, TIMO (2002). Multiple, compound and intersectional discrimination: bringing the experiences of the most marginalized to the fore. Turku: Institute for Human Rights, Abo Akademi University.

NUSSBAUM, MARTHA C. (1999). Sex and social justice. New York: Oxford University Press.

NUSSBAUM, MARTHA C. (2006). El ocultamiento de lo humano. Repugnancia, vergüenza y ley. Buenos Aires: Katz.

NUSSBAUM, MARTHA C. (2010). From Disgust to Humanity. Sexual Orientation and Constitutional Law. New York, Oxford University Press.

OSBORNE, RAQUEL y MOLINA PETIT, CRISTINA (2008). Presentación. En EMPIRIA. Revista de Metodología de Ciencias Sociales, 15, 147-182.

PATEMAN, CAROLE (1995). El contrato sexual. México: Anthropos/UAM.

PNUD (2009): "Transversalización de la diversidad". Recuperado de http://www.americalatinagenera.org/es/documentos/20100223_tranversalizacion_de_la_diversidad.pdf

RODRÍGUEZ PALOP, MARÍA EUGENIA (2011). Claves para entender los nuevos derechos humanos. Madrid: Libros de la Catarata.

SÁNCHEZ-MORENO, MANUEL (2011). Enfoque de derechos humanos en el desarrollo. Aspectos teóricos y metodológicos. Revista de Fomento Social, 261, 39-71.

SÁNCHEZ-MORENO, MANUEL (2012). La CEDAW desde dentro. Visiones y revisiones de sus artículos interpretativos. Democracia y Derechos, 1(2), 110-135.

SÁNCHEZ-MORENO, MANUEL (2018). Del sexo al cuerpo. Evolución histórica y jurídica de las violencias de género en el derecho internacional humanitario y el derecho penal internacional. Papeles el tiempo de los derechos, 22.

SÁNCHEZ-MORENO, MANUEL (2020). Pasado y presente: la memoria democrática en Europa y su relevancia ante el postfascismo. En PALOMA GONZÁLEZ DEL MIÑO (dir.), El sistema internacional del siglo XXI: dinámicas, actores y relaciones internacionales (pp. 251-266). Madrid: Tirant Lo Blanch. 
SANCHIS VIDAL, AMELIA (2012): "Epistemología, feminismo y género: investigando sin complejos”. Recuperado de https://www.researchgate.net/publication/281749647_ Epistemologia_feminismo_y_genero_investigando_sin_complejos

SANCHIS VIDAL, AMELIA (2015): Interpretación jurídica, igualdad y género en los estudios de derecho. Aportaciones epistémicas y feministas. Revista General de Derecho Constitucional, 21, 33-40.

SCARRY, ELAINE (1985). The Body in Pain: The Making and Unmaking of the World. New York: Oxford UP.

SEDWICK KOSOFSKY, EVE (1998). Epistemología del armario. Barcelona: Ediciones de la Tempestad.

SEGATO, RITA LAURA (2003). Las estructuras elementales de la violencia. Ensayos sobre género entre la antropología, el psicoanálisis y los derechos humanos. Bernal: Universidad Nacional de Quilmes/Prometeo.

SPIVAK, GAYATRI CHAKRAVORTY (2010). Crítica de la razón poscolonial. Hacia una historia del presente evanescente. Madrid: Akal.

VALDES, FRANCISCO (1998). Beyond Sexual Orientation in Queer Legal Theory: Majoritarianism, Multidimensionality, and Responsibility in Social Justice Scholarship or Legal Scholars as Cultural Warriors. Denver University Law Review, 75, 1409-1464.

YOUNG, IRIS M. (1990). La justicia y la política de la diferencia. Madrid: Ed. Cátedra.

ZIZEK, SLAVOJ (2008). Cómo leer a Lacan. Buenos Aires: Paidós. 